\title{
In situ aromatase expression in primary tumor is associated with estrogen receptor expression but is not predictive of response to endocrine therapy in advanced breast cancer
}

\author{
Anne E Lykkesfeldt*†1, Katrine L Henriksen ${ }^{\dagger 1}$, Birgitte B Rasmussen ${ }^{2}$, \\ Hironobu Sasano ${ }^{3}$, Dean B Evans ${ }^{4}$, Susanne Møller ${ }^{5}$, Bent Ejlertsen ${ }^{6}$ and \\ Henning T Mouridsen ${ }^{7}$
}

\begin{abstract}
Address: ${ }^{1}$ Department of Tumor Endocrinology, Institute of Cancer Biology, Danish Cancer Society, DK- 2100 Copenhagen $\varnothing$, Denmark, ${ }^{2}$ Department of Pathology, Herlev Hospital, DK-2730, Denmark, ${ }^{3}$ Department of Pathology, Tohoku University School of Medicine, Sendai 9808575, Japan, ${ }^{4}$ Novartis Institutes for BioMedical Research, CH-4002 Basel, Switzerland, ${ }^{5}$ Danish Breast Cancer Cooperative Group, Rigshospitalet, DK- 2100 Copenhagen $\varnothing$, Denmark, ${ }^{6}$ Department of Oncology, Rigshospitalet, DK- 2100 Copenhagen $\varnothing$, Denmark and ${ }^{7}$ Danish Breast Cancer Cooperative Group, Rigshospitalet, DK- 2100 Copenhagen Ø, Denmark

Email: Anne E Lykkesfeldt* - al@cancer.dk; Katrine L Henriksen - khe@cancer.dk; Birgitte B Rasmussen - bibrra01@heh.regionh.dk; Hironobu Sasano - hsasano@patholo2.med.tohoku.ac.jp; Dean B Evans - dean.evans@novartis.com; Susanne Møller - sm@dbcg.dk; Bent Ejlertsen - bent.ejlertsen@rh.regionh.dk; Henning T Mouridsen - mou@dbcg.dk

* Corresponding author †Equal contributors
\end{abstract}

Published: 16 June 2009

BMC Cancer 2009, 9:185 doi:10.1186/147|-2407-9-185

This article is available from: http://www.biomedcentral.com//47/-2407/9//85

(C) 2009 Lykkesfeldt et al; licensee BioMed Central Ltd.

This is an Open Access article distributed under the terms of the Creative Commons Attribution License (http://creativecommons.org/licenses/by/2.0), which permits unrestricted use, distribution, and reproduction in any medium, provided the original work is properly cited.

\begin{abstract}
Background: New, third-generation aromatase inhibitors (Als) have proven comparable or superior to the anti-estrogen tamoxifen for treatment of estrogen receptor (ER) and/or progesterone receptor (PR) positive breast cancer. Als suppress total body and intratumoral estrogen levels. It is unclear whether in situ carcinoma cell aromatization is the primary source of estrogen production for tumor growth and whether the aromatase expression is predictive of response to endocrine therapy. Due to methodological difficulties in the determination of the aromatase protein, COX-2, an enzyme involved in the synthesis of aromatase, has been suggested as a surrogate marker for aromatase expression.
\end{abstract}

Methods: Primary tumor material was retrospectively collected from 88 patients who participated in a randomized clinical trial comparing the Al letrozole to the anti-estrogen tamoxifen for first-line treatment of advanced breast cancer. Semi-quantitative immunohistochemical (IHC) analysis was performed for ER, PR, COX-2 and aromatase using Tissue Microarrays (TMAs). Aromatase was also analyzed using whole sections (WS). Kappa analysis was applied to compare association of protein expression levels. Univariate Wilcoxon analysis and the Cox-analysis were performed to evaluate time to progression (TTP) in relation to marker expression.

Results: Aromatase expression was associated with ER, but not with PR or COX-2 expression in carcinoma cells. Measurements of aromatase in WS were not comparable to results from TMAs. Expression of COX-2 and aromatase did not predict response to endocrine therapy. Aromatase in combination with high PR expression may select letrozole treated patients with a longer TTP.

Conclusion: TMAs are not suitable for IHC analysis of in situ aromatase expression and we did not find COX-2 expression in carcinoma cells to be a surrogate marker for aromatase. In situ 
aromatase expression in tumor cells is associated with ER expression and may thus point towards good prognosis. Aromatase expression in cancer cells is not predictive of response to endocrine therapy, indicating that in situ estrogen synthesis may not be the major source of intratumoral estrogen. However, aromatase expression in combination with high PR expression may select letrozole treated patients with longer TTP.

Trial registration: Sub-study of trial P025 for advanced breast cancer.

\section{Background}

Treatment with the non-steroidal antiestrogen (AE) tamoxifen has been the first-line endocrine treatment of choice for breast cancer patients for more than 30 years. However, the third-generation aromatase inhibitors (AIs) anastrozole, letrozole and exemestane have in large randomized trials shown to be comparable or superior to tamoxifen as treatment for postmenopausal women with hormone receptor (HR) positive metastatic breast cancer [1-6]. The objective response rates ranged from $21 \%$ to $33 \%$ with clinical benefit rate varying between $49 \%$ and $59 \%[1,2,4]$, necessitating improvements in treatments and development of response predictors to the different options.

Expression of the estrogen receptor (ER) is a prerequisite for estrogen dependent tumor growth and ER positivity in the primary tumor has been used as a selection criterion for endocrine therapy since 1975 [7]. Furthermore, ER is also well known to be an important prognostic factor, indicating good prognosis [8]. The progesterone receptor $(\mathrm{PR})$ is an estrogen-inducible protein and improved response rates have been seen in tumors, which besides ER, also express PR [9-11], with increasing ER and PR scores being associated with better response to tamoxifen in ER positive metastatic breast cancer [12]. Today, most laboratories perform immunohistochemical (IHC) determination of both ER and PR and a good correlation between the quantitative level determined with the classical ligand-binding assays and the immunohistochemical scores have been found for both ER and PR [12].

The third-generation AIs anastrozole, letrozole and exemestane suppress total-body aromatization by $98 \%$, more than $99 \%$ and $98 \%$, respectively $[13,14]$, demonstrating the superior suppressive potency of these drugs compared to the previous first- and second-generation compounds [15]. Furthermore in studies with direct measurements of estrogen levels in tumor tissue, AI treatment resulted in nearly complete suppression of intratumoral estrogen levels [16-20]. The intratumoral estrogen level may arise from local estrogen production in carcinoma cells or surrounding cells as well as from the uptake of peripherally generated estrogens, and so it has been debated whether the in situ estrogen production in the carcinoma cells is the major contributor to estrogen-stimu- lated tumor growth and thus may be a predictor of response to treatment with AIs [14,21-24]. Biochemically determined intratumoral aromatase enzyme activity has shown correlation with response to treatment with AI [25], and classic estrogen-dependent genes and proliferation markers changed in most tumors during treatment irrespective of response [26], supporting the hypothesis that in situ estrogen synthesis may be used as a predictive marker for response to treatment with aromatase inhibitor. Attempts have been made to measure the aromatase protein in the tumor tissue as an alternative to the biochemical assay. The aromatase protein has been detected in both fibroblasts, adipose cells, benign duct cells and invasive cancer cells and the results have been contradictory with respect to which cell types in the breast express the aromatase protein [27-33]. A promising new aromatase antibody (\#677) has shown immunoreactivity in carcinoma cells, stromal cells or fibroblasts, adipocytes, normal epithelium, and inflammatory cells [31]. The multiplicative SIP score for carcinoma cells ("Proportion of aromatase immunopositivity" multiplied with "Relative intensity of aromatase immunoreactivity") was positively correlated with the aromatase enzyme activity measured by the biochemical tritiated-water release assay [32], indicating that aromatase expression in the carcinoma cells may be a predictive marker for response to AI treatment. Furthermore, since PR expression is induced by estrogen binding to ER, it may be hypothesised that high PR expression in combination with aromatase expression in primary tumor tissue identifies patients with superior benefit from AI treatment.

Due to the difficulties regarding determination of the aromatase protein expression and activity, cyclooxygenase- 2 (COX-2) has been proposed as a surrogate marker for aromatase expression [34]. COX-2 is an isoform of the prostaglandin endoperoxidase synthetase that catalyzes key steps in the metabolism of arachidonic acid to prostaglandin E2 (PGE2), thereby regulating the synthesis of aromatase [35-37]: Expression of aromatase is controlled by unique promoters that lie upstream of tissue-specific exons. These first exons are alternatively spliced onto a common site upstream of the translation initiation codon in exon II. The aromatase mRNAs have unique 5'-untranslated regions, but the sequences encoding the aromatase enzyme are identical. In tumor tissue aromatase is up reg- 
ulated by switching from the weak promoter I.4 to the strong promoters IIa and I.3. Switching from promoter I.4 to IIa and I.3 is likely to be mediated by the induction of COX-2 [38], which is expressed in a variety of cancers including invasive breast cancer [39-41].

The aim of this study was to explore whether the expression level of the aromatase protein in carcinoma cells alone or in combination with PR expression in the primary tumor may be predictive for response to treatment with the AI letrozole or the AE tamoxifen in the advanced breast cancer setting. The predictive utility of COX-2 for endocrine treatment as well as a surrogate marker for aromatase expression was also investigated. We have prepared tissue micoarrays (TMAs) and performed IHC analyses of ER, PR, COX-2 and aromatase in primary tumor tissue from 88 of the 907 patients who participated in the multicenter randomized phase III P025 trial which compared first-line tamoxifen or letrozole treatment in postmenopausal women with locally advanced or metastatic breast cancer $[2,3]$. A semi-quantitative IHC score has been determined for each of the four parameters. For aromatase expression, an evaluation of IHC staining in whole sections versus staining in TMAs was performed as previously described for ER, PR and COX-2 [42].

\section{Methods}

This study was derived from the P025 study, an international, multicenter, double-blind, randomized, two-arm, phase III clinical trial comparing letrozole with tamoxifen as first-line treatment for postmenopausal women with advanced breast cancer [2]. The P025 study was conducted in accordance with the ethical principles that originated in the Helsinki II declaration and the appropriate local ethics review boards have approved the study, number by local ethical review board: 01025-KF12-13899.

For this current sub-study it was possible to collect primary tumor material from 68 Danish patients and from 20 patients from the rest of Europe. Thus, altogether, paraffin blocks containing primary tumor material from 88 patients were collected. Sixty-five tumors were classified as invasive ductal and 12 as invasive lobular carcinoma. Three tumor samples were classified as neither lobular nor ductal and eight samples were not suitable for classification. Three of the 88 patients were originally allocated to a combination treatment of letrozole and tamoxifen. This combination therapy arm was stopped in the original P025 study and the patients were excluded from the intention to treat analysis, thus 85 patients are included in the present study, unless for comparison of aromatase expression in WS and TMAs where tissue from all 88 tumors were included. The end-point Time To Progression (TTP), is defined as described by Mouridsen et al. 2001 [2]. All patient data used in this study were provided by Novartis Phama AG, (Basel Switzerland) to the Danish Breast Cancer Cooperative Group (DBCG), following agreement with the departments who treated the patients.

\section{Immunohistochemical staining of ER, PR and COX-2}

Sections, $3 \mu \mathrm{m}$, were dewaxed in coconut oil and rehydrated in a graded series of ethanol. Slides were preheated for $10 \mathrm{~min}$. and boiled for $15 \mathrm{~min}$. in microwave oven at $600 \mathrm{~W}$ in TEG buffer ( $\mathrm{pH}=9$, Bie \& Berntsen, Denmark) for antigen retrieval and rinsed in tap water. All immunostainings were performed at room temperature using the automated immunostainer Tech-mate 500 (Dako, Denmark), according to the following protocol: Slides were washed in TBS $+0.1 \%$ BRIJ-35 detergent (AX-LAB, Denmark) and incubated with primary antibody diluted in TBS + 0.1\% BRIJ-35 + 1\% BSA (Bovine Serum Albumin) + $15 \mathrm{nM}$ sodiumazide for $60 \mathrm{~min}$. After washing, endogenous peroxidase activity was blocked using $3 \% \mathrm{H}_{2} \mathrm{O}_{2}$ in TBS + 0.1\% BRIJ-35. The ChemMate EnVision+ Detection Kit (Peroxidase/Dab, Rabbit/Mouse, K5007, Dako, Denmark) was used as detection system for the primary antibodies. After washing, slides were counterstained with haematoxylin and dehydrated in graded series of ethanol, and finally mounted with Pertex (Histolab, Denmark). The following primary antibodies, all monoclonal mouse

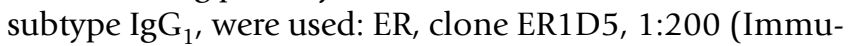
notech); PR, clone 16, 1:200 (Novocastra); COX-2, no $6111104,1: 150$ (Cayman Chemicals). The specificity of the immunoreactions was verified by substitution of the primary antibody with the corresponding concentration of mouse $\mathrm{IgG}_{1}, \mathrm{X} 0931$ (Dako, Denmark). In addition, positive control slides with breast tumor tissue or other tissue known to stain positive were included in every run. All stainings of the individual antigens were performed in a single run in order to minimize interserial staining variation.

\section{Immunohistochemical staining of Aromatase}

All aromatase staining as well as evaluation of the staining was conducted by the author Hironobu Sasano. Sections, $3 \mu \mathrm{m}$, were stained and analyzed as described in Sasano et al. 2005 [32]. In brief: tissue sections were immunostained by a biotin-streptavidin method using a Histofine kit (Nichirei Co. Ltd., Tokyo, Japan). The antigen-antibody complex was subsequently visualized with 3.3'diaminobenzidine solution (DAB) and counterstained with hematoxylin. Evaluation of aromatase IHC was performed by assessing the approximate percentage of carcinoma cell staining (proportion score) and classifying the proportion score values as the following: $0=<1 \%, 1=1-$ $25 \%, 2=26-50 \%, 3=51-75 \%$ and $4=76-100 \%$ immunopositive cells. The relative intensity of aromatase immune-positive cells was classified as follows: $0=$ no immunoreactivity, 1 = weak, 2 = moderate and 3 = intense 
immunoreactivity. The SIP score is the proportion score multiplied with the relative intensity score. The evaluation of the aromatase immunoreactivity was performed without the knowledge of response to treatment.

\section{Preparation of tissue microarrays}

TMA blocks were constructed using the TMA-builder from Histopathology Ltd. (AH-diagnostics, Denmark). Targets for arraying (areas with representative invasive tumor) were identified by marking the corresponding areas on haematoxylin-eosin stained sections from each paraffin block. Two tissue cores with a diameter of $2 \mathrm{~mm}$ were transferred from each donor block to the recipient TMA block. Kidney tissue was placed in the first core of the upper left and right corner of the TMA block to ensure correct orientation when examining the slides. All analyses were performed on TMAs [42], whereas analysis for aromatase was performed on whole sections (WS) as well.

\section{Evaluation of ER, PR and COX-2 immunohistochemical staining}

All specimens were evaluated without knowledge of the clinical data. TMA slides were evaluated by light microscopy and the authors Katrine L. Henriksen scored all the samples and Birgitte B. Rasmussen has been consulted in cases of doubt. Only invasive tumor components were considered when assessing the staining. Semi-quantitative determination of ER and PR was performed according to the method described by Allred et al. [43]. This method was also used for semi-quantitative determination of the non-nuclear cytoplasmatic marker COX-2. In brief: The proportion of positive stained cells was judged as $0=$ no cells stained, 1 = between 0 and $1 \%$ stained positive, 2 = between 1 and 10\% stained positive, 3 = between 10 and $33 \%$ stained positive, 4 = between 33 and $66 \%$ stained positive, 5 = between 66 and 100\% stained positive. In addition to the proportion score, an intensity score was made based on the average intensity of staining, $0=$ negative, 1 = weak, 2 = intermediate and 3 = strong. The intensity score and the proportion score was added to obtain the total score referred to as the Allred score, which is 0 or between 2 and 8, 0 and 2 were interpreted as negative. Only nuclear staining was judged when scoring ER and PR, whereas cytoplasmatic staining was scored for COX-2.

\section{Evaluation of Aromatase immunohistochemical staining}

Evaluation of aromatase staining in WS was done using the SIP score as described in Sasano et al. 2005 [32]. As described above, when preparing TMAs only areas containing primary tumor was used, thus instead of determining a SIP score the determination of "relative intensity of aromatase immunoreactivity" in carcinoma cells was scored for TMAs and not the "proportion of aromatase immunopositivity". Consequently no SIP score was obtained for the TMA sections.

\section{Statistical Analysis}

Chi-square test was used to evaluate if the patients in the present study represent the entire study population of patients. The Kappa score was used to evaluate the agreement of aromatase immunointensity of carcinoma cells on whole sections (WS) versus TMAs, and for this analysis results from all 88 collected tumor samples were included. The Systematic difference between the scores on TMA and whole sections was analysed with Wilcoxon's Signed Rank Sum test on the difference (TMA-WS) and the Concordance is determined as the number of samples with no difference in scoring value in relation to the number of samples with a different scoring value and $P$-values for evaluation of WS versus TMA are given (Table 1). The association of aromatase expression with COX-2, as well as the agreement between expression of aromatase with ER and PR was done by calculating the Kappa score and $P$ values are given. Time to progression (TTP) was the primary endpoint in the P025 trial and was defined as the interval between the date of randomisation and the earliest date of disease progression. Kaplan-Meier plots were used to illustrate univariate survival and differences in TTP between subgroups were evaluated by the Wilcoxons rank sum test. A multivariate Cox proportional hazards model was used to investigate the effect of treatment and each of the parameters aromatase, COX-2 and PR, expressed as semi-quantitative IHC results. Interaction between treatment and aromatase expression was further investigated by subgroup analysis within each treatment group. When analysis of grouped scoring values was applied, scoring values were grouped as follows: For ER, PR and COX-2expression "high" is defined as Allred score 7 or 8, "low" as Allred score 3 to 6 and "negative" as 0 or 2. For Aromatase, "high" is defined as SIP score 9 and 12, "low" as SIP score 1,2,3,4,6 or 8, and "negative" as SIP score 0 (See Table 2). In all tests, a $P$-value $<0.05$ was used as level of significance.

Table I: Comparison of carcinoma cell aromatase immunointensity in TMA and WS

\begin{tabular}{lccc}
\hline TMA versus WS $\mathbf{n}=69$ & Concordance & Test for no difference & Kappa score \\
\cline { 2 - 4 } & $26 \%$ & $(P<0.002)$ & $\begin{array}{c}0.0048(-0.080-0.17) \\
(P=0.4 I)\end{array}$ \\
\hline
\end{tabular}


Table 2: Semi-quantitative IHC results: ER, PR, COX-2 and Aromatase

\begin{tabular}{|c|c|c|c|c|}
\hline & & Let $n=46$ & Tam n = 39 & Total $(n=85)$ \\
\hline \multicolumn{5}{|l|}{ ER level (Allred score) } \\
\hline negative & $\leq 2$ & 3 & 2 & 5 \\
\hline \multirow[t]{4}{*}{ Low } & 3 & 0 & 0 & 0 \\
\hline & 4 & I & 1 & 2 \\
\hline & 5 & 2 & 1 & 3 \\
\hline & 6 & 6 & 3 & 9 \\
\hline \multirow[t]{2}{*}{ High } & 7 & 10 & 8 & 18 \\
\hline & 8 & 21 & 19 & 40 \\
\hline N.A. (not assessable) & & 3 & 5 & 8 \\
\hline Total positive & & 40 & 32 & 72 \\
\hline \multicolumn{5}{|l|}{ PR level (Allred score) } \\
\hline negative & $\leq 2$ & 9 & 9 & 18 \\
\hline \multirow[t]{4}{*}{ Low } & 3 & 3 & 1 & 4 \\
\hline & 4 & 5 & 3 & 8 \\
\hline & 5 & 4 & 5 & 9 \\
\hline & 6 & I & 6 & 7 \\
\hline \multirow[t]{2}{*}{ High } & 7 & 6 & 0 & 6 \\
\hline & 8 & 14 & 12 & 26 \\
\hline N.A. (not assessable) & & 4 & 3 & 7 \\
\hline Total positive & & 33 & 27 & 60 \\
\hline \multicolumn{5}{|c|}{ COX-2 level (Allred score) } \\
\hline negative & $\leq 2$ & 13 & 11 & 24 \\
\hline \multirow[t]{4}{*}{ Low } & 3 & 0 & 2 & 2 \\
\hline & 4 & 5 & 4 & 9 \\
\hline & 5 & 10 & 2 & 12 \\
\hline & 6 & 7 & 6 & 13 \\
\hline \multirow[t]{2}{*}{ High } & 7 & 5 & 7 & 12 \\
\hline & 8 & 1 & 0 & I \\
\hline
\end{tabular}


Table 2: Semi-quantitative IHC results: ER, PR, COX-2 and Aromatase (Continued)

\begin{tabular}{|c|c|c|c|c|}
\hline N.A. (not assessable) & & 5 & 7 & 12 \\
\hline Total positive & & 28 & 21 & 49 \\
\hline \multicolumn{5}{|c|}{ Aromatase level (Carcinoma cell SIP score) } \\
\hline negative & 0 & 10 & 5 & 15 \\
\hline \multirow[t]{6}{*}{ Low } & 1 & 3 & 3 & 6 \\
\hline & 2 & 9 & 3 & 12 \\
\hline & 3 & 2 & 3 & 5 \\
\hline & 4 & 5 & 9 & 14 \\
\hline & 6 & 8 & 5 & 13 \\
\hline & 8 & 0 & 2 & 2 \\
\hline \multirow[t]{2}{*}{ High } & 9 & 2 & 3 & 5 \\
\hline & 12 & 2 & 1 & 3 \\
\hline N.A. (not assessable) & & 5 & 5 & 10 \\
\hline Total positive & & 30 & 30 & 60 \\
\hline
\end{tabular}

\section{Results}

\section{Patient data}

The P025 trial recruited 907 patients and archived paraffin embedded tissue was collected from the primary tumor of 88 patients, of which 85 (9.4\%) could be included in the clinical analyses [2]. As in the original study, the patients (85) are well balanced according to treatment allocation, 46 (54\%) to letrozole and 39 (46\%) to tamoxifen, age at randomization and Karnofsky Performance Score. However, the assessable patients differed from the total trial cohort with respect to having a significantly more advanced stage of disease at study entry and with respect to a larger proportion having received prior adjuvant treatment with tamoxifen $(P<0.01)$. In our subgroup of 85 patients the median TTP for letrozole treatment was 9.5 months (90\% range: $0.33-39$ ) and 9.5 months (90\% range: 2.6-46) for tamoxifen. More detailed patient data are given in Henriksen et al. 2009 [44].

\section{Evaluation of aromatase staining in whole sections versus tissue microarrays}

All of the collected 88 tumor samples were used for comparison, but for 19 of the samples either the WS or TMA results were missing due to technical reasons, thus 69 measurements were compared (Table 1). For 18 of the 69 tumors the same aromatase carcinoma cell intensity score was obtained from WS and TMA, resulting in a concordance of $26 \%$. In 13 cases, the result obtained on TMA was higher than the result from WS, and for 38 of the samples WS scores were higher than TMA. A test for symmetry disclosed a systematic difference $(P=0.0013)$ and a significant difference was confirmed by the Signed Rank test $(P$ $<0.002)$. We have further compared the expression level of carcinoma cell staining intensity by Kappa statistics and found that results obtained from WS and TMAs were not significantly associated $(P=0.41)$. Figure 1 shows examples of aromatase staining of breast tumor tissue from WS and TMAs. High aromatase expression in carcinoma cells is shown in Figure $1 \mathrm{~A}$ and $1 \mathrm{~B}$, whereas $1 \mathrm{C}$ and $1 \mathrm{D}$ show low aromatase expression in carcinoma cells. Figure $1 \mathrm{E}$ and $1 \mathrm{~F}$ illustrate a discordant staining result with high score in WS and low score in TMA.

\section{Scoring results of IHC staining of ER, PR, COX-2 and aromatase}

ER, PR and COX-2 levels were scored by the Allred score on TMAs, as we have previously shown concordance between scores on TMAs and WS [42], whereas aromatase was analyzed on WS and evaluated by the SIP score. The semi-quantitative scoring results of ER, PR, COX-2 and aromatase are shown in Table 2. For all four markers the 


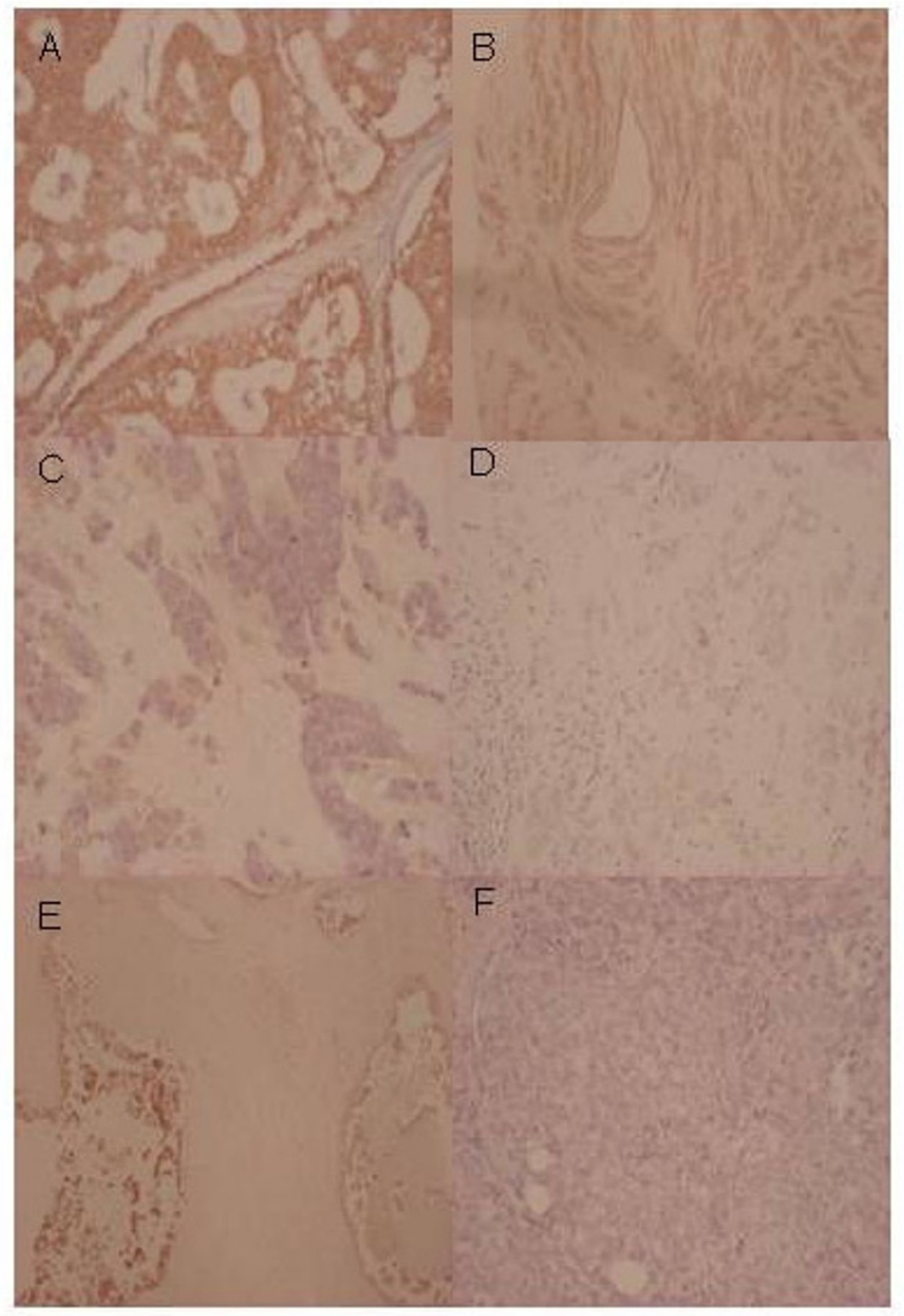

Figure I

Representative pictures of immunohistochemical aromatase staining of primary breast tumor tissue with the antibody \#677. (A) WS with high level of aromatase expression. (B) TMA with high level of aromatase expression. (C) WS with low level of aromatase expression. (D) TMA with low level of aromatase expression. (E) WS from a tumor showing heterogeneity in carcinoma cell staining intensity scored as high expression (score value 9). (F) A TMA illustrating discordant low intensity score (score value I). 
distribution of semi-quantitative scoring results were well balanced. The majority of tumors had a high Allred score for ER and PR. Only $6 \%$ of the tumors are scored negative for ER, $16 \%$ are scored low and $68 \%$ are scored high. The PR is more evenly distributed on the Allred scale, $21 \%$ of the tumors are scored negative, $33 \%$ low and $38 \%$ of the patients have a high expression of PR. None of the tumors were negative for both ER and PR. High cytoplasmic staining of COX-2 was observed in 15\% of the samples, $42 \%$ showed low COX-2 expression, and 28\% were negative. The majority of tumours stained positive for aromatase, $61 \%$ with low expression and $9 \%$ were scored as high, whereas $18 \%$ was scored negative for the aromatase protein. For all markers technical problems impaired the scoring of between 7 and 12 of the tumor samples making them "not assessable" (N.A.).

\section{Association between aromatase expression and COX-2, $E R$ and $P R$}

To examine the association between tumor cell aromatase expression and the supposed surrogate marker COX-2, we performed Kappa statistics. Furthermore, the association between aromatase and ER as well as the estrogen-regulated protein PR was evaluated. Aromatase expression was not found to be associated with the expression of either COX-2 $(P=0.46)$ or PR $(P=0.83)$. However, a strong trend towards an association between tumor cell expression of aromatase and ER was found, $(P=0.057)$.

A

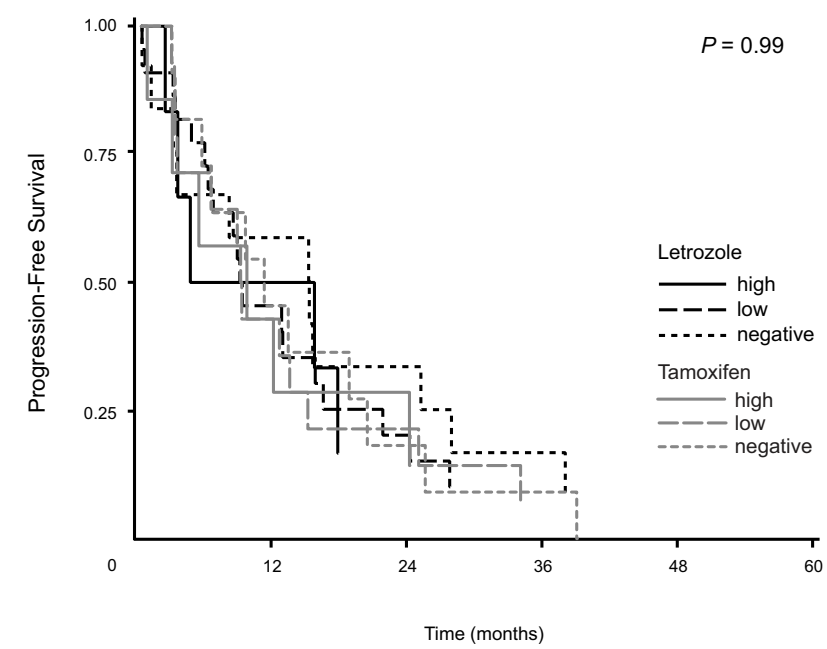

COX-2 and aromatase expression for selection of treatment with either letrozole or tamoxifen

To evaluate whether our IHC analyses of either COX-2 or aromatase expression could be used to discriminate between TTP for patients treated with tamoxifen or letrozole, we compared TTP for all patients separated in subgroups of negative, low or high expression of the two markers. For each marker TTP was compared by uni-variate Wilcoxon-test and Kaplan-Meier plots as shown in Figure 2. Neither COX-2 nor aromatase expression was associated with superiority of either letrozole or tamoxifen in terms of TTP, $P=0.99$ and $P=0.72$ respectively. In agreement, a Cox analysis of COX-2 and aromatase expression level in relation to total endocrine treatment (letrozole- and tamoxifen-treated patients together) disclosed no difference in TTP between patients with negative, low or high marker expression, $P=0.95$ and $P=0.94$ for COX-2 and aromatase, respectively.

\section{Aromatase and PR expression for selection of treatment with either letrozole or tamoxifen}

As described above, we have compared the expression level of aromatase with ER and PR by Kappa statistics, and whereas the PR expression level was independent of aromatase expression, a strong trend towards association of aromatase and ER was found $(P=0.057)$. Thus, aromatase positivity combined with PR expression might add information regarding TTP for patients treated with tamoxifen

B

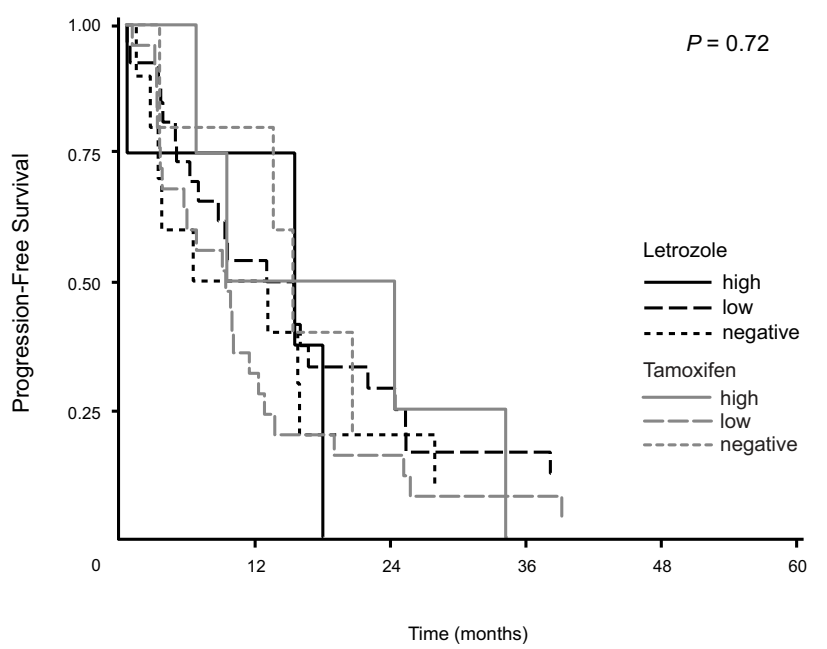

Figure 2

Time to progression (TTP) according to high, low and negative expression of COX-2 and Aromatase in primary tumor tissue for patients treated with either letrozole (black) or tamoxifen (grey). (A) TTP according to COX-2 expression: Letrozole treatment, COX-2 high, $n=6$; COX-2 low, $n=22$; COX-2 negative, $n=13$. Tamoxifen treatment, COX-2 high, $n=7$; COX-2 low, $n=14$; COX-2 negative, $n=1$ I. (B) TTP according to Aromatase expression: Letrozole treatment, Aromatase high, $n=4$; Aromatase low, $n=27$; Aromatase negative, $n=10$. Tamoxifen treatment, Aromatase high, $n=4$; Aromatase low, $n=25$; Aromatase negative, $n=4$. 
or letrozole. When looking at all patients (letrozole- and tamoxifen-treated patients together), Cox analysis disclosed a significant difference between TTP for patients with aromatase positive tumors with negative, low and high PR content $(P=0.023)$, with high PR associated with long TTP. A further subgroup analysis of tamoxifen- and letrozole-treated patients showed a strong trend towards a different TTP for patients treated with letrozole $(P=$ $0.059)$, but not for tamoxifen treated patients $(P=0.14)$, Figure $3 \mathrm{~A}$ and $3 \mathrm{~B}$.

\section{Discussion}

In this small retrospective sub-study of the P025 trial we have analyzed aromatase, COX-2, ER and PR expression by semi-quantitative IHC in primary tumor material from 9.4\% of the patients included in the original study. The patients in our study were rather equally distributed regarding allocation to letrozole or tamoxifen. Our aim was to investigate whether aromatase- or COX-2 expression could be used as single markers for treatment, or if aromatase in combination with PR expression, could be used to select patients for treatment with either tamoxifen or letrozole. Furthermore, the utility of COX-2 as a surrogate IHC marker for aromatase as well as the feasibility of analysing aromatase expression by TMAs was evaluated.

In spite of the many resources and efforts applied to understand the basis of development, progression and prediction of response to treatment of breast cancer, only three predictive markers (ER, PR and HER-2) are recommended for routine IHC testing in breast cancer. Two of these, ER and PR, are predictive for response to endocrine treatment [45]. Since aromatase is the key enzyme in the estrogen synthesis and is expressed in both breast carcinoma cells, surrounding stromal cells as well as endothelial and benign breast cells [27,34], many attempts have been made to evaluate the importance of aromatase expression in the different cell types in the breast for local estrogen production and for utility as prognostic and predictive marker. The obtained results have been contradictory $[26-29,33,46,47]$. However, recent data have shown that the aromatase antibody \#677 is very specific for IHC detection of the aromatase protein [31,32]. Although it has been assumed that the estrogen production in the surrounding stromal cells contributes significantly to the estrogen level within the carcinoma cells, it was found that only the IHC staining of aromatase in the carcinoma cells was correlated to the aromatase enzyme activity in the breast tissue [32]. Therefore, in this study we have firstly evaluated whether carcinoma cell aromatase detection with the \#677 antibody gave comparable results in TMA and WS. The observed systematic difference and higher aromatase carcinoma cell staining intensity in WS compared to TMA can be explained by the marked heterogeneity of aromatase expression in the tumor tissue as illustrated in Figure 1E. Thus, the present study can not support TMA analysis of aromatase and accordingly, we have used the aromatase results obtained from WS when
A

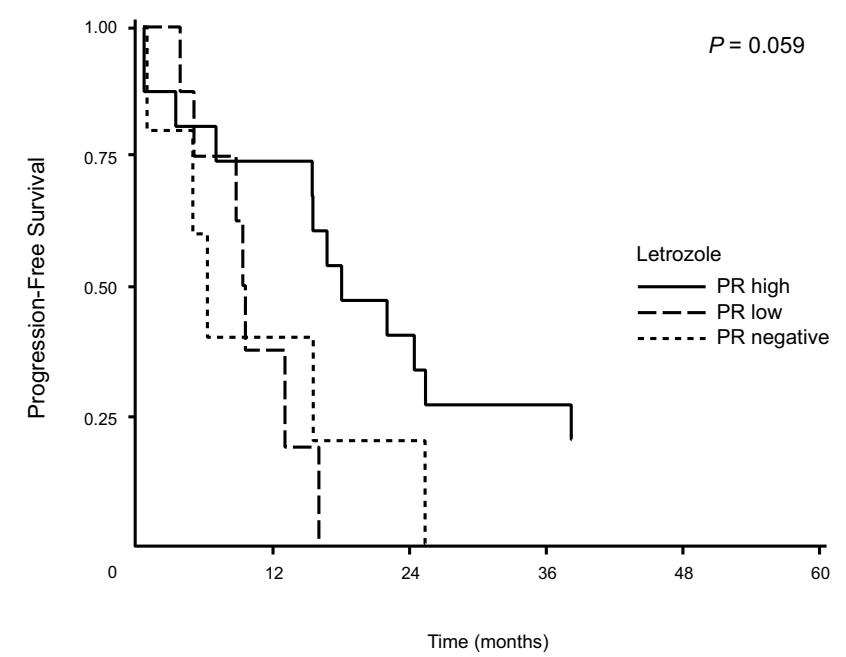

B

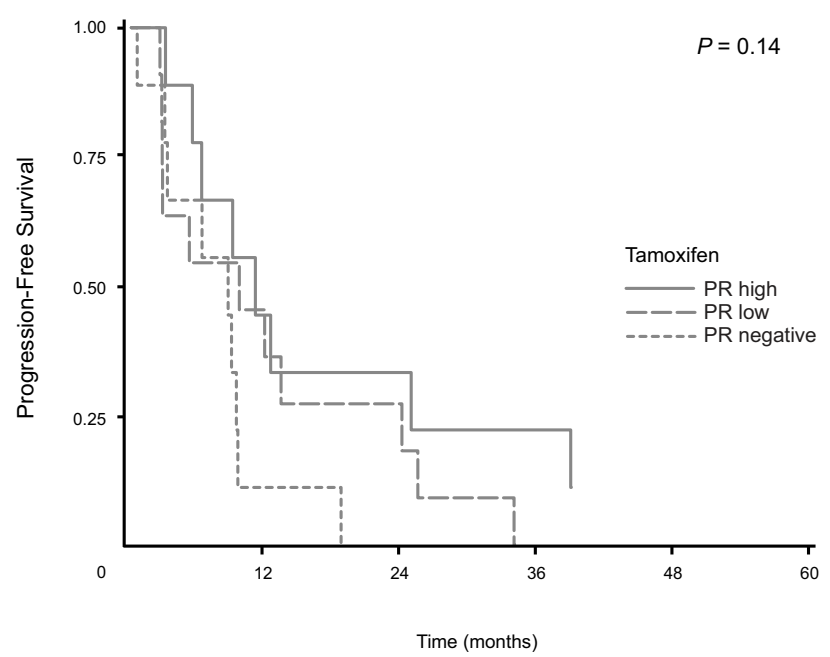

\section{Figure 3}

Time to progression (TTP) according to high, low and negative PR expression in aromatase positive primary tumours from patients treated with letrozole or tamoxifen. (A) Letrozole treatment, Aromatase positive, PR high, $n$ = 16; Aromatase positive, PR low, $n=8$; Aromatase positive, PR neg., $n=5$. (B) Tamoxifen treatment, Aromatase positive, PR high, $\mathrm{n}=$ 9; Aromatase positive, PR low, $\mathrm{n}=1$ I; Aromatase positive, PR neg., $\mathrm{n}=9$. 
analyzing aromatase expression in relation to COX-2, ER and PR.

As mentioned previously, COX-2 is an enzyme that regulates the production of prostaglandins, which in turn regulate the synthesis of aromatase [36,37]. Several studies have found association between COX-2 expression and aromatase expression at the transcriptional level $[35,36,48]$, and at the protein level using IHC $[27,49,50]$, supporting that COX-2 may be used as a surrogate marker for aromatase content in tumor tissue [41]. This is in contrast to our finding, in which we compared the expression of COX-2 and aromatase in invasive carcinoma cells scored by semi-quantitative IHC and found no association between the aromatase expression (SIP score) and COX-2 expression (Allred score). We assume that the lack of association may be due to the complex regulation of the aromatase expression and activity, involving both COX-2 induced prostaglandins, but also many other stimulatory compounds e. g. cyclic-adenosine-monophosphate, glucocorticoids, interleukine- 6 and tumor necrosis factor- $\alpha[26,51-57]$.

We found no association between carcinoma aromatase and PR expression, whereas a strong trend towards association between aromatase and ER in the carcinoma cells was found. This result is supported by Miki et al. who found no correlation between PR status and aromatase mRNA expression level in carcinoma cells and a significant association between aromatase mRNA and ER status in carcinoma cells [58]. This would imply that in situ estrogen production in the carcinoma cells is not the major source for ER-induced PR expression, an observation also supported by another recent study [46] in which aromatase, like ER, was expressed in inherently less aggressive tumors.

In carcinoma cells neither COX-2 nor aromatase expression alone were able to select groups of patients with superior benefit from tamoxifen therapy, but for patients with aromatase positive tumors a high PR expression identified a group of patients for whom endocrine treatment resulted in significantly longer TTP $(P=0.023)$. For letrozole treatment, patients with aromatase positive tumor cells and high PR expression had longer progression free survival $(P=0.059)$. This was not observed for patients treated with tamoxifen, indicating that in advanced disease the superiority of letrozole to tamoxifen is primarily observed in the group of patients with aromatase positive and high PR expression in the primary tumor cells.

\section{Conclusion}

In summary, our results suggest that aromatase is too heterogeneously expressed in tumor tissue to allow detection in TMAs with $2 \mathrm{~mm}$ core size. COX-2 expression in breast carcinoma cells was not found to be a surrogate marker of aromatase expression, and neither COX-2 nor aromatase expression in carcinoma cells predicted response to letrozole or tamoxifen treatment. The lack of association between PR and in situ aromatase expression as well as no predictive value of aromatase expression for response to endocrine therapy, suggest that the estrogen synthesis in the carcinoma cells is not the major source for intratumoral estrogen. The strong trend towards an association of in situ carcinoma aromatase expression with ER expression may point towards aromatase as indicator of a good prognosis. In advanced disease, carcinoma cell aromatase expression in combination with high PR expression may select letrozole treated patients with longer time to progression.

\section{Competing interests}

D. B. Evans is an employee and share holder of Novartis Pharma AG. The rest of the authors declare that they have no competing interests.

\section{Authors' contributions}

AEL supervised the study and participated in drafting and writing of the manuscript. KLH carried out the IHC studies of COX-2, ER and PR and participated in drafting and writing of the manuscript. BBR supervised the IHC studies of COX-2, ER and PR and participated in writing the manuscript. HS carried out all IHC studies of aromatase. SM performed the statistical analysis. DE, BE and HM has participated in its design and coordination. All authors read and approved the final manuscript.

\section{Acknowledgements}

We kindly acknowledge the participating Danish and European Pathology Departments for supplying paraffin embedded tumor material: Aalborg Sygehus, Bispebjerg Hospital, Hjørring Sygehus, Hvidovre Hospital, Nykøbing Falster Sygehus, Odense Universitetshospital, Rigshospitalet, Roskilde Sygehus, Slagelse Sygehus, Svendborg Sygehus, Sønderborg Sygehus, Vejle Sygehus, Viborg Sygehus, J.W. Goethe-Universität, Universitätsklinikum Hamburg-Eppendorf, Centre Regional Francois Baclesse, Centre Hospitalier Général André-Boulloche, Kuopio University Hospital and Turku University Hospital. Katsuhiko Ono, Department of Pathology, Tohoku University School of Medicine, Japan and Birgit S. Hansen, Annegrethe Schaadt, Vinni Bredahl, and Heidi Frogne, Department of Pathology, Roskilde Sygehus, Roskilde, Denmark are acknowledged for excellent technical assistance. This study was supported financially by "Fonden til fremme af klinisk eksperimentiel cancerforskning specielt vedrørende cancer mammae" and Novartis Pharma AG Basel, Switzerland.

\section{References}

I. Bonneterre J, Buzdar A, Nabholtz JM, Robertson JF, Thurlimann B, von EM, et al.: Anastrozole is superior to tamoxifen as first-line therapy in hormone receptor positive advanced breast carcinoma. Cancer 2001, 92:2247-2258.

2. Mouridsen H, Gershanovich M, Sun Y, Perez-Carrion R, Boni C, Monnier A, et al.: Superior efficacy of letrozole versus tamoxifen as first-line therapy for postmenopausal women with advanced breast cancer: results of a phase III study of the International 
Letrozole Breast Cancer Group. J Clin Oncol 200I, 19:2596-2606

3. Mouridsen H, Gershanovich M, Sun Y, Perez-Carrion R, Boni C, Monnier A, et al.: Phase III study of letrozole versus tamoxifen as first-line therapy of advanced breast cancer in postmenopausal women: analysis of survival and update of efficacy from the International Letrozole Breast Cancer Group. I Clin Oncol 2003, 21:2101-2109.

4. Nabholtz JM, Buzdar A, Pollak M, Harwin W, Burton G, Mangalik A, et al.: Anastrozole is superior to tamoxifen as first-line therapy for advanced breast cancer in postmenopausal women: results of a North American multicenter randomized trial. Arimidex Study Group. J Clin Oncol 2000, 18:3758-3767.

5. Paridaens RJ, Dirix LY, Beex LV, Nooij M, Cameron DA, Cufer T, et al.: Phase III Study Comparing Exemestane With Tamoxifen As First-Line Hormonal Treatment of Metastatic Breast Cancer in Postmenopausal Women: The European Organisation for Research and Treatment of Cancer Breast Cancer Cooperative Group. J Clin Oncol 2008, 26:4883-4890.

6. Wardley A: The need for advanced breast cancer treatment guidelines: results of an internet-based survey. Breast 2008, 17:275-28I.

7. Jensen EV: Estrogen receptors in hormone-dependent breast cancers. Cancer Res 1975, 35:3362-3364.

8. Early Breast Cancer Trialists'Collaborative Group (EBCTCG): Effects of chemotherapy and hormonal therapy for early breast cancer on recurrence and 15-year survival: an overview of the randomised trials. Lancet 2005, 365:1687-17/7.

9. Bardou VJ, Arpino G, Elledge RM, Osborne CK, Clark GM: Progesterone receptor status significantly improves outcome prediction over estrogen receptor status alone for adjuvant endocrine therapy in two large breast cancer databases. J Clin Oncol 2003, 21:1973-1979.

10. Osborne CK, Yochmowitz MG, Knight WA III, McGuire WL: The value of estrogen and progesterone receptors in the treatment of breast cancer. Cancer 1980, 46:2884-2888.

II. Viale G, Regan MM, Maiorano E, Mastropasqua MG, Dell'Orto P, Rasmussen BB, et al.: Prognostic and predictive value of centrally reviewed expression of estrogen and progesterone receptors in a randomized trial comparing letrozole and tamoxifen adjuvant therapy for postmenopausal early breast cancer: BIG I-98. J Clin Oncol 2007, 25:3846-3852.

12. Elledge RM, Green S, Pugh R, Allred DC, Clark GM, Hill J, et al.: Estrogen receptor (ER) and progesterone receptor (PgR), by ligand-binding assay compared with ER, PgR and pS2, by immuno-histochemistry in predicting response to tamoxifen in metastatic breast cancer: a Southwest Oncology Group Study. Int J Cancer 2000, 89: III-II7.

13. Geisler J, Haynes B, Anker G, Dowsett M, Lonning PE: Influence of letrozole and anastrozole on total body aromatization and plasma estrogen levels in postmenopausal breast cancer patients evaluated in a randomized, cross-over study. J Clin Oncol 2002, 20:751-757.

14. Geisler J: Breast cancer tissue estrogens and their manipulation with aromatase inhibitors and inactivators. J Steroid Biochem Mol Biol 2003, 86:245-253.

15. Geisler J, Lonning PE: Aromatase inhibition: translation into a successful therapeutic approach. Clin Cancer Res 2005, I I:2809-282I.

16. Reed MJ, Owen AM, Lai LC, Coldham NG, Ghilchik MW, Shaikh NA, et al.: In situ oestrone synthesis in normal breast and breast tumour tissues: effect of treatment with 4-hydroxyandrostenedione. Int J Cancer 1989, 44:233-237.

17. de Jong PC, van d V, Nortier HW, Maitimu-Smeele I, Donker TH, Thijssen $\mathrm{JH}$, et al:: Inhibition of breast cancer tissue aromatase activity and estrogen concentrations by the third-generation aromatase inhibitor vorozole. Cancer Res 1997, 57:2109-2 III.

18. Geisler J, Berntsen H, Lonning PE: A novel HPLC-RIA method for the simultaneous detection of estrone, estradiol and estrone sulphate levels in breast cancer tissue. I Steroid Biochem Mol Biol 2000, 72:259-264.

19. Geisler J, Detre S, Berntsen H, Ottestad L, Lindtjorn B, Dowsett M, et al:: Influence of neoadjuvant anastrozole (Arimidex) on intratumoral estrogen levels and proliferation markers in patients with locally advanced breast cancer. Clin Cancer Res 200I, 7:1230-I236.
20. Geisler J, Helle H, Ekse D, Duong NK, Evans DB, Nordbo Y, et al:: Letrozole is Superior to Anastrozole in Suppressing Breast Cancer Tissue and Plasma Estrogen Levels. Clin Cancer Res 2008, 14:6330-6335.

21. Miller WR, Hawkins RA, Forrest AP: Significance of aromatase activity in human breast cancer. Cancer Res 1982, 42:3365s-3368s.

22. Miller WR, O'Neill JS: The significance of steroid metabolism in human cancer. J Steroid Biochem Mol Biol 1990, 37:3 I7-325.

23. Santner SJ, Feil PD, Santen RJ: In situ estrogen production via the estrone sulfatase pathway in breast tumors: relative importance versus the aromatase pathway. J Clin Endocrinol Metab 1984, 59:29-33.

24. Sasano H, Suzuki T, Miki Y, Moriya T: Intracrinology of estrogens and androgens in breast carcinoma. I Steroid Biochem Mol Biol 2008, 108: $181-185$

25. Miller WR, Anderson TJ, Evans DB, Krause A, Hampton G, Dixon JM: An integrated view of aromatase and its inhibition. J Steroid Biochem Mol Biol 2003, 86:413-42I.

26. Miller WR, Larionov A, Anderson T], Walker JR, Krause A, Evans DB et al.: Predicting response and resistance to endocrine therapy: profiling patients on aromatase inhibitors. Cancer 2008, I I 2:689-694.

27. Brodie A, Lu Q, Yue W, Wang J, Liu Y: Intratumoral aromatase model: the effects of letrozole (CGS 20267). Breast Cancer Res Treat I998, 49(Suppl I):S23-S26.

28. Esteban JM, Warsi Z, Haniu M, Hall P, Shively JE, Chen S: Detection of intratumoral aromatase in breast carcinomas. An immunohistochemical study with clinicopathologic correlation. Am J Pathol 1992, 140:337-343.

29. Santen RJ, Martel J, Hoagland M, Naftolin F, Roa L, Harada N, et al.: Demonstration of aromatase activity and its regulation in breast tumor and benign breast fibroblasts. Breast Cancer Res Treat 1998, 49(Suppl I):S93-S99.

30. Sasano $\mathrm{H}$, Murakami $\mathrm{H}$ : Immunolocalization of aromatase in human breast disorders using different antibodies. Breast Cancer Res Treat 1998, 49(SuppI I):S79-S84.

3I. Sasano H, Edwards DP, Anderson TJ, Silverberg SG, Evans DB, Santen RJ, et al: Validation of new aromatase monoclonal antibodies for immunohistochemistry: progress report. J Steroid Biochem Mol Biol 2003, 86:239-244.

32. Sasano H, Anderson TJ, Silverberg SG, Santen RJ, Conway M, Edwards DP, et al.: The validation of new aromatase monoclonal antibodies for immunohistochemistry - a correlation with biochemical activities in 46 cases of breast cancer. I Steroid Biochem Mol Biol 2005, 95:35-39.

33. Shenton KC, Dowsett M, Lu Q, Brodie A, Sasano H, Sacks NP, et al: Comparison of biochemical aromatase activity with aromatase immunohistochemistry in human breast carcinomas. Breast Cancer Res Treat 1998, 49(Suppl I):SI0I-SI07.

34. Brodie AM, Lu O, Long BJ, Fulton A, Chen T, Macpherson N, et al: Aromatase and COX-2 expression in human breast cancers. J Steroid Biochem Mol Biol 200I, 79:4|-47.

35. Brueggemeier RW, Su B, Sugimoto Y, az-Cruz ES, Davis DD: Aromatase and COX in breast cancer: enzyme inhibitors and beyond. I Steroid Biochem Mol Biol 2007, 106:16-23.

36. Richards JA, Petrel TA, Brueggemeier RW: Signaling pathways regulating aromatase and cyclooxygenases in normal and malignant breast cells. I Steroid Biochem Mol Biol 2002, 80:203-2/2.

37. Simpson ER, Mahendroo MS, Means GD, Kilgore MW, Hinshelwood MM, Graham-Lorence S, et al.: Aromatase cytochrome P450, the enzyme responsible for estrogen biosynthesis. Endocr Rev 1994, 15:342-355.

38. Kamat A, Hinshelwood MM, Murry BA, Mendelson CR: Mechanisms in tissue-specific regulation of estrogen biosynthesis in humans. Trends Endocrinol Metab 2002, 13:122-128.

39. Ristimaki A, Sivula A, Lundin J, Lundin M, Salminen T, Haglund C, et al.: Prognostic significance of elevated cyclooxygenase-2 expression in breast cancer. Cancer Res 2002, 62:632-635.

40. Barnes N, Haywood P, Flint P, Knox WF, Bundred NJ: Survivin expression in in situ and invasive breast cancer relates to COX-2 expression and DCIS recurrence. Br / Cancer 2006, 94:253-258 
4I. Singh-Ranger G, Salhab M, Mokbel K: The role of cyclooxygenase2 in breast cancer: review. Breast Cancer Res Treat 2008, 109:189-198.

42. Henriksen KL, Rasmussen BB, Lykkesfeldt AE, Moller S, Ejlertsen B, Mouridsen HT: Semi-quantitative scoring of potentially predictive markers for endocrine treatment of breast cancer: a comparison between whole sections and tissue microarrays. J Clin Pathol 2007, 60:397-404.

43. Allred DC, Harvey JM, Berardo M, Clark GM: Prognostic and predictive factors in breast cancer by immunohistochemical analysis. Mod Pathol 1998, I 1:155-168.

44. Henriksen KL, Rasmussen BB, Lykkesfeldt AE, Moller S, Ejlertsen B, Mouridsen HT: An ER activity profile including ER, PR, Bcl-2 and IGF-IR may have potential as selection criterion for letrozole or tamoxifen treatment of patients with advanced breast cancer. Acta Oncol 2009, 48:522-53I.

45. Harris L, Fritsche H, Mennel R, Norton L, Ravdin P, Taube S, et al.: American Society of Clinical Oncology 2007 update of recommendations for the use of tumor markers in breast cancer. J Clin Oncol 2007, 25:5287-53I2.

46. Ellis MJ, Miller WR, Tao Y, Evans DB, Chaudri Ross HA, Miki Y, et al.: Aromatase expression and outcomes in the P024 neoadjuvant endocrine therapy trial. Breast Cancer Res Treat 2009, I I6(2):37I-3I8

47. Ellis MJ, Tao Y, Luo J, A'Hern R, Evans DB, Bhatnagar AS, et al.: Outcome prediction for estrogen receptor-positive breast cancer based on postneoadjuvant endocrine therapy tumor characteristics. J Natl Cancer Inst 2008, I00: I 380-I388.

48. Salhab M, Singh-Ranger G, Mokbel R, Jouhra F, Jiang WG, Mokbel K Cyclooxygenase- 2 mRNA expression correlates with aromatase expression in human breast cancer. J Surg Oncol 2007 96:424-428

49. Gunnarsson C, Jansson A, Holmlund B, Ferraud L, Nordenskjold B, Rutqvist LE, et al.: Expression of COX-2 and steroid converting enzymes in breast cancer. Oncol Rep 2006, 16:219-224.

50. Oliveira VM, Piato S, Silva MA: Correlation of cyclooxygenase-2 and aromatase immunohistochemical expression in invasive ductal carcinoma, ductal carcinoma in situ, and adjacent normal epithelium. Breast Cancer Res Treat 2006, 95:235-24I.

51. Cirillo D, Rachiglio AM, la MR, Giordano A, Normanno N: Leptin signaling in breast cancer: An overview. J Cell Biochem 2008, I 05:956-964.

52. Hardy DB, Janowski BA, Chen CC, Mendelson CR: Progesterone receptor inhibits aromatase and inflammatory response pathways in breast cancer cells via ligand-dependent and ligand-independent mechanisms. Mol Endocrinol 2008, 22: $1812-1824$

53. Macdiarmid F, Wang D, Duncan LJ, Purohit A, Ghilchick MW, Reed MJ: Stimulation of aromatase activity in breast fibroblasts by tumor necrosis factor alpha. Mol Cell Endocrinol I994, 106:17-2I

54. Reed MJ, Coldham NG, Patel SR, Ghilchik MW, James VH: Interleukin- $I$ and interleukin- 6 in breast cyst fluid: their role in regulating aromatase activity in breast cancer cells. J Endocrinol 1992, 132:R5-R8.

55. Zhao Y, Mendelson CR, Simpson ER: Characterization of the sequences of the human CYPI9 (aromatase) gene that mediate regulation by glucocorticoids in adipose stromal cells and fetal hepatocytes. Mol Endocrinol 1995, 9:340-349.

56. Zhao Y, Agarwal VR, Mendelson CR, Simpson ER: Estrogen biosynthesis proximal to a breast tumor is stimulated by PGE2 via cyclic AMP, leading to activation of promoter II of the CYP I 9 (aromatase) gene. Endocrinology 1996, 137:5739-5742.

57. Purohit A, Ghilchik MW, Leese MP, Potter BV, Reed MJ: Regulation of aromatase activity by cytokines, PGE2 and 2-methoxyoestrone-3-O-sulphamate in fibroblasts derived from normal and malignant breast tissues. J Steroid Biochem Mol Biol 2005, 94:167-I72.

58. Miki Y, Suzuki T, Tazawa C, Yamaguchi Y, Kitada K, Honma S, et al: Aromatase localization in human breast cancer tissues: possible interactions between intratumoral stromal and parenchymal cells. Cancer Res 2007, 67:3945-3954.

\section{Pre-publication history}

The pre-publication history for this paper can be accessed here: http://www.biomedcentral.com/1471-2407/9/185/pre pub
Publish with Biomed Central and every scientist can read your work free of charge

"BioMed Central will be the most significant development for disseminating the results of biomedical research in our lifetime. "

Sir Paul Nurse, Cancer Research UK

Your research papers will be:

- available free of charge to the entire biomedical community

- peer reviewed and published immediately upon acceptance

- cited in PubMed and archived on PubMed Central

- yours - you keep the copyright 